\title{
The role of regional climate projections in managing complex socio-ecological systems
}

\author{
Joseph David Daron • Kate Sutherland • \\ Christopher Jack $\cdot$ Bruce C. Hewitson
}

Received: 15 November 2013/Accepted: 2 May 2014/Published online: 21 May 2014

(c) The Author(s) 2014. This article is published with open access at Springerlink.com

\begin{abstract}
Climate is one of many factors to be considered in adapting systems to environmental and societal change and often it is not the most important factor. Moreover, given considerable model inadequacies, irreducible uncertainties, and poor accessibility to model output, we may legitimately ask whether or not regional climate projections ought to have a central role in guiding climate change adaptation decisions. This question is addressed by analysing the value of regional downscaled climate model output in the management of complex socio-ecological systems (SESs) vulnerable to climate change. We demonstrate, using the example of the Dwesa-Cwebe region in South Africa, that the management of such systems under changing environmental and socio-economic conditions requires a nuanced and holistic approach that addresses cross-scale system interdependencies and incorporates "complexity thinking". We argue that the persistent focus on increasing precision and skill in regional climate projections is misguided and does not adequately address the needs of society. However, this does not imply that decision makers should exclude current and future generations of regional climate projections in their management processes. On the contrary, ignoring such information, however uncertain and incomplete, risks the implementation of maladaptive policies and practices. By using regional
\end{abstract}

Editor: Wolfgang Cramer.

Electronic supplementary material The online version of this article (doi:10.1007/s10113-014-0631-y) contains supplementary material, which is available to authorised users.

J. D. Daron $(\bowtie) \cdot$ K. Sutherland · C. Jack · B. C. Hewitson Climate System Analysis Group, University of Cape Town, Cape Town, South Africa

e-mail: jdaron@csag.uct.ac.za climate projections to further explore uncertainties and investigate cross-scale system dependencies, such information can be used to aid understanding of how SESs might evolve under alternative future societal and environmental scenarios.

Keywords Resilience $\cdot$ Uncertainty · Adaptation · Model projections $\cdot$ Sensitivity

\section{Introduction}

Acknowledging complexity when responding to contemporary environmental and societal pressures requires us to think and behave differently. Complex systems, which contain multiple interacting elements, feedbacks, nonlinearities and regime behaviour (Burkett et al. 2005), are characterised by cross-scale spatial and temporal interactions (Peters et al. 2004, 2007). If such cross-scale interactions are important within a socio-ecological system (SES-discussed in detail in Sect. 2) sensitive to climate variability and change, then climate information on different scales may also be highly relevant in understanding and managing the system. However, producing reliable and actionable climate model projections (i.e. containing evidence strong enough to guide real-world decisions) on regional and local scales is complicated by the need to resolve, and accurately simulate, climatic processes at high spatial resolutions; a computationally expensive and timeconsuming endeavour. Given these and other notable constraints (see Hewitson et al. 2013 and Sect. 5), it is difficult to assess the value of the information content from regional climate downscaling (RCD) for different decision contexts. Here, we argue that despite these significant challenges, RCD can be used to better understand the 
sensitivity of complex SESs to climate change and is therefore a relevant source of information for guiding SES management decisions.

There are multiple working definitions of climate (Lorenz 1995; Daron 2012; IPCC 2013), but here we consider climate as the distribution of atmosphere-ocean states consistent with specific external forcing conditions; climate change is a change in this distribution. In order to simulate the climate system and inform societal decisions, climate scientists rely conventionally on experiments using general circulation models (GCMs) which currently resolve atmosphere and ocean processes at horizontal resolutions of approximately 100-200 km (Randall et al. 2007; Taylor et al. 2012; IPCC 2013). Yet decision makers tasked with adapting systems and processes to climate variability and change are usually more interested in the climate at finer spatial scales (Adger et al. 2005). This scale mismatch causes a problem for both scientists striving to provide defensible model projections and for users who are required to interpret climate model output. To bridge this gap, the climate science community has developed dynamical downscaling approaches using regional climate models (RCMs) and empirical-statistical downscaling (ESD) methodologies (Giorgi 1990; Frey-Buness et al. 1995; Murphy 2000; Benestad 2004; Hewitson and Crane 2006), providing higher spatial resolution information over specific regions of interest. Yet far from simplifying matters, practitioners are now required to interpret both GCM information and regional downscaled model information which is conditioned on the imperfect GCM output. How then might practitioners use this wealth of information for guiding adaptation decisions given the need to consider a wide range of other non-climatic factors? The answer is not straightforward. Here we attempt to provide insight to address this question, acknowledging the uncertainties and constraints associated with the current generation of RCD approaches. We focus on the management of SESs and draw on recent methodological developments in the theory of complex systems to better understand how RCD output might be interpreted and communicated to inform adaptation decisions.

\section{Socio-ecological systems as complex adaptive systems}

Historically, the ecological and social sciences have developed largely independently. Yet, as observed by Berkes et al. (2003), there is an emerging consensus regarding the need to draw on different disciplinary approaches and find mutually beneficial solutions to social and ecological issues. This has led to an increased emphasis on SES research as a holistic approach to understand systems with multiple components (Young et al. 2006; Ohl et al. 2007). SESs are those systems in which social-incorporating cultural, political, economic and technological-and ecological components interact, emphasising the "human-in-nature" perspective (Resilience Alliance 2010). Ostrom (2009) states that one of the core challenges in determining why some SESs are sustainable and others collapse is the identification and analyses of relationships at multiple levels and at different spatial and temporal scales. To fully understand the dynamics and interactions within complex SESs, we therefore need to determine and analyse cross-scale system relationships and interdependencies.

Resilient systems have the capacity to lead a continued existence by absorbing or adapting to change (Holling 1986; Adger 2000). Contemporary research on the management of SESs builds on the concepts of complexity and resilience, viewing SESs as complex adaptive systems which are "characterised by historical (path) dependency, nonlinear (non-convex) dynamics, regime shifts, multiple basins of attraction and limited predictability" (Stockholm Resilience Centre 2007). In managing SESs as complex adaptive systems, we shift away from the advocacy of aggressive controlling measures, which can be vulnerable to errors in the predicted future state, towards dynamic responsive approaches that aim to bolster resilience through softer, less intrusive interventions. Such responsive management approaches are not well served by top-down policy-prescriptive climate science. Rather, responsive approaches require alternative forms of analysis where climate is embedded in the wider decision context.

Lempert et al. (2004) distinguish between a "predictthen-act" framing of climate risk and an "assess-risk-ofpolicy" framing of climate risk. In managing SESs as complex adaptive systems in a changing climate, the latter framing is more appropriate. However, even in an assessrisk-of-policy framing, the process of exploring system sensitivities and vulnerabilities can follow linear thinking; first establishing the range of available policy or adaptation interventions, identifying climate thresholds and then mapping the available adaptation options to the range of plausible future scenarios in order to find the most suitable, and robust (Wilby and Dessai 2010), adaptation strategythough the approach put forward by Wilby and Dessai (2010) does stress the need for long-term monitoring to support adaptive management. While it is pragmatically attractive to use a linear approach, we risk assigning too much confidence to the assumptions embedded in the analysis process. Furthermore, even the decision to frame the investigation of vulnerability and adaptation decision making process with a "climate lens" dictates, to a certain extent, the scope of the analysis (O'Brien et al. 2007). By focussing only on managing the risks of climate variability and climate change, we might forego adaptation pathways 
which are better able to cope with a broad range of future societal and environmental risks.

\section{Rethinking climate complexity with "complexity thinking"}

There is no universally accepted definition of complexity, but here we consider a complex system as an open system containing multiple interacting elements, feedback loops (Kastens et al. 2009) and nonlinear relationships (Haken and Mikhailov 1993). Cilliers (1998) states that in a complex system, the "whole cannot be fully understood by analysing its components." For SESs and complex systems more generally, we should not therefore expect the combined wisdom of different scientific disciplines working in isolation to coalesce and reliably inform our understanding of the entire system. An interdisciplinary perspective is not only desirable but essential, drawing on disciplinary expertise while providing a holistic interpretation of the system being investigated (Klein 2004). Achieving this in practice, however, is only possible when we have the appropriate tools and sufficient institutional capacity (Agrawal 2010; Mustelin et al. 2013).

It is one thing to acknowledge that a system is complex and quite another to incorporate the principles of complexity into the management of that system. Invoking complexity thinking requires decision makers to grapple with the multiple nonlinear interactions that define and influence the emergent behaviour of the system (Funtowicz and Ravetz 1994; Jenson 1998). One of the primary challenges in engaging with a complex system is deciding which variables might be defined as endogenous (internal) and exogenous (external) to the system. Ostrom (2009) identifies climate as an exogenous variable for SES management, thereby decoupling changes in climate, in itself a complex system (Rind 1999), to the dynamic behaviour of a SES. While this may be necessary for pragmatic reasons, we question whether or not management interventions, which affect the dynamics of a SES, can feedback to the local and regional climate. The answer is presumably scale dependent. For example, in the case of a large SES, such as the Amazon rainforest or the Yangtze river delta, management interventions (e.g. prohibiting deforestation or expanding irrigation) could have significant impacts on regional and local climatic conditions (Gao et al. 2007; Batlle Bayer et al. 2012). Indeed, biogeophysical feedbacks, linked to land use change, can lead to regional climate impacts (Pielke et al. 2002), but there remains a lack of interdisciplinary studies to thoroughly investigate such interactions (Bonan 2008). At these scales, and for specific regions, any RCD method that does not account for land use change impacts (be it explicitly through land use parameterisation schemes or through post-processing) could provide misleading output (e.g. Preuschmann and Jacob 2012). Conversely, for smaller systems, incorporating the climate as a dynamic component may be unnecessary; considering climate as an exogenous variable, which can directly or indirectly affect multiple SES components, will suffice.

Figure 1 shows two conceptual diagrams of a SES analysis framework which incorporate climate as an exogenous (Fig. 1a) and endogenous (Fig. 1b) component. One could also imagine a similar characterisation whereby the economy and sociopolitical environment are considered as either exogenous or endogenous components of the system, but here our focus is on the climate. For a relatively small scale SES, characterising climate as exogenous to the system (Fig. 1a) would likely be more appropriate as it is not a dominant component of the internal SES dynamics but rather changes in the real (or perceived) climate act to mould or manoeuvre the system to different states. Whether these SES states are stable or unstable depends on the internal dynamics of the system. However, when considering such a system as part of a larger aggregated SES, perhaps at the scale of the district or province, it might become appropriate to consider climate as endogenous to the system (Fig. 1b). For example, if management practices substantially change land use affecting surface runoff into the rivers feeding the SES of interest, then evapotranspiration rates will respond and alter rates of atmospheric heat exchange, thus impacting the local climate and feeding back to the resource ecology of the SES. An understanding of such system dynamics could constrain the available management options. Our decision therefore rests both on the scale at which management interventions can be taken and on the emergent scale $^{1}$ at which socio-ecological changes feedback to the regional and local climate. Defining and establishing the emergent scale in practice is non-trivial and requires a comprehensive understanding of SES-dependent feedback mechanisms; regional climate modelling experiments could help in this regard. In most adaptation contexts, however, identifying this scale will be a challenge, but acknowledging this challenge will encourage decision makers to consider the possible unintended consequences of adaptation decisions.

Our characterisation of climate as endogenous or exogenous to the system changes the role of climate information in the management process. At the national and international policy scale, the consideration of certain interventions and policy directives (e.g. UN-REDD 2012)

\footnotetext{
1 The scale at which organised dynamic behaviour is observed (or emerges), resulting from the combination of apparently uncoordinated microscale processes.
} 

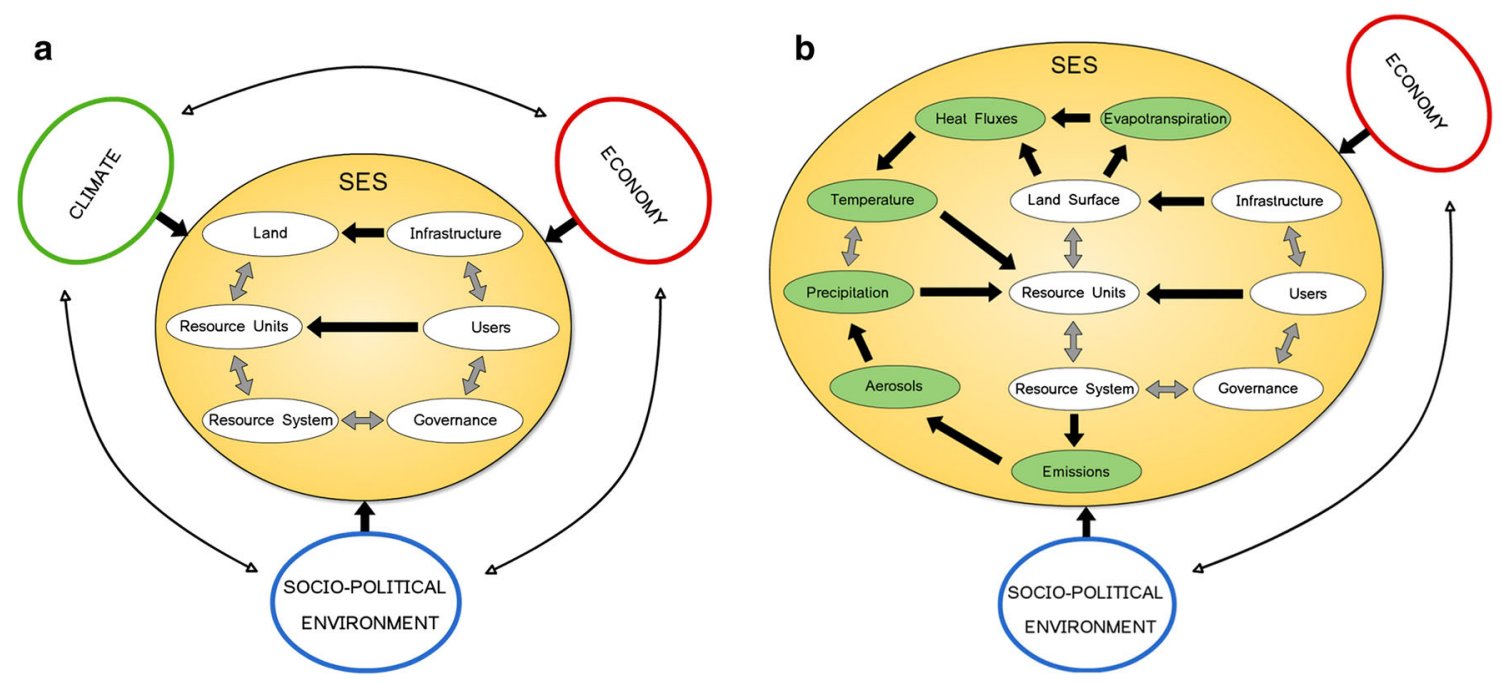

Fig. 1 Conceptual diagrams representing the core components of a socio-ecological system, based on Ostrom (2009), with climatic factors considered $\mathbf{a}$ exogenous and $\mathbf{b}$ endogenous to the system

might be informed by considering climate as endogenous to the SESs under investigation. In such situations, RCD, and in particular dynamical downscaling methods, can be used to enhance understanding of long-term SES responses. At the local policy and decision making scale, it is usually more appropriate to consider climate as exogenous to the SES, but does that mean that RCD becomes less important or even completely unnecessary? To better explore these issues, we describe a SES which is highly sensitive to both societal and environmental change.

\section{The Dwesa-Cwebe SES}

In this section, we analyse the Dwesa-Cwebe SES to illustrate the complexities of incorporating RCD into management decisions. While no specific empirical data regarding local vulnerabilities and adaptation strategies have been gathered as part of this study, the authors have been engaging with the local communities for a number of years to better understand the system and identify critical issues which impact vulnerability, acknowledging the complexities and evolving dynamics of the system. We therefore use the Dwesa-Cwebe SES as a worked example to highlight the challenges in using RCD to guide realworld decisions.

Located in the Eastern Cape on the southeast coast of South Africa (in the former Transkei), the Dwesa and Cwebe areas are separated by the Mbashe river and together form the Dwesa-Cwebe Nature Reserve (Timmermans and Naicker 2002). The extended Dwesa-Cwebe region, situated between the Nqabara and the Ntlonyana rivers, covers approximately $235 \mathrm{~km}^{2}$ and comprises two state forest reserves, a national marine reserve and four inland and adjacent communal areas (see Supplementary Materials, Fig. S1). Bounding any SES is problematic, and like many other systems, the Dwesa-Cwebe SES is part of a much bigger SES; Fay (2007) highlights the historical challenges of agreeing boundaries in Dwesa-Cwebe. The region is rich in resources, supports a diverse ecosystem and contains a number of small settlements with a present population of approximately 15,000 people (Fox 1997; Fay 2011).

The Dwesa-Cwebe region is both naturally diverse and socially complex. The region is one of the poorest in South Africa and is characterised by temporary urban migration and reliance on remittances and state welfare grants (Timmermans 2004). After forced removal of indigenous communities from the Dwesa and Cwebe forests between the 1890 s and 1930s, those communities that remained eventually lost all access to the natural resources under Apartheid. Following the collapse of Apartheid in the early 1990s, communities began a struggle for land restitution under South Africa's Land Restitution policy. The residents were subsequently awarded full title to the communal land and a "Deed of Settlement" in which the DwesaCwebe Land Trust was granted full control of the protected area (Department of Land Affairs 2001; Palmer et al. 2002). Although not without tension and controversy, according to Palmer et al. (2002), this is one of the very few South African examples of successful reconciliation between protected areas and the interests of local residents. Historically administered separately, both Dwesa and Cwebe now fall under the administration of the Mbashe Municipality.

The region is situated within a climatic transition zone between the temperate south coast and the subtropical north coast and is characterised by wet summers and dry 


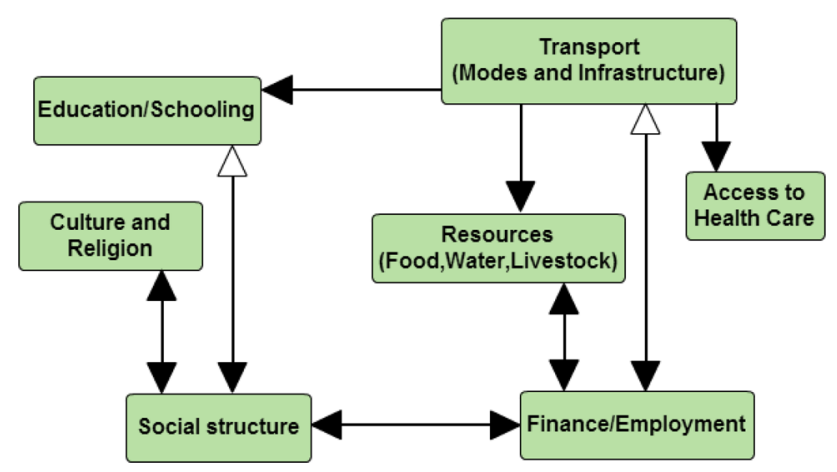

Fig. 2 Conceptual diagram of the Dwesa SES from a household perspective. Black arrows indicate a strong dependency and white arrows indicate a weak dependency

winters. Agricultural cycles are closely linked to the seasonal distribution of rainfall thereby influencing the seasonal pattern of resource harvesting (McAllister 1999). Variations in the onset of the rainy season can affect crop production impacting local food security. Poorly developed infrastructure and a high dependence on subsistence agriculture (Kepe 2005) mean that communities are strongly reliant on the successful functioning of natural and social systems to meet their basic livelihood needs.

Figure 2 shows the different components of the DwesaCwebe SES when considering the system at the household scale. The figure represents a conceptual, and largely hypothetical, diagram identifying the main system components, relationships and strength of dependencies. It was developed after holding individual and group discussions with members of the community and engaging with other researchers who have been interacting with the community over a number of years (e.g. AESEDA 2014). We can use this diagram to think about the system interactions and consequences of shocks to the system following major climatic events. During discussions members of the community recollected a heavy rainfall event at the end of the last decade that led to flooding which permanently destroyed a major bridge across the Mbashe river. This impacted the communication and connectivity between the two communities separated by the river. Without the bridge, the only way to move people and goods safely is by using a much longer route inland. Individuals who previously walked, or used ox-drawn sledges (a local mode of transport for people and goods) to travel between the communities, now have to travel further and make use, where possible, of motorised vehicles to transport resources, food and people, incurring a significant additional financial cost.

Flooding events cause the poorly maintained roads to deteriorate further. This has knock-on impacts to the other components of the system, affecting availability of resources (food, water, livestock), access to education and health care, as well as the ability for people to attend religious and cultural events. In addition, community members, especially younger generations, often move to cities for work but longer travel times, as a result of poor roads, reduces the number of home visits. This impacts the exchange of finances between the migrant workers and their families who are largely dependent on this financial support. Reduced income from household migrant workers prevents children from attending school, due to the high cost of transporting children to and from school and the need for the children to stay at home to assist in farm work (Timmermans 2004). The poor roads also impact the local tourism sector, which provides additional employment for local people.

Climatic events not only have major impacts on the livelihoods of people in the Dwesa-Cwebe communities but also affect the reserve and other ecological components of the system. The Dwesa-Cwebe system has abundant natural capital, including forests, grasslands, water resources and marine ecosystems. Periods of low or high rainfall can impact the available water resources, as well as runoff in the rivers and the estuarine dynamics. Changes in local climate conditions (particularly rainfall and temperature) can therefore influence the functioning and efficiency of the natural capital. To effectively manage the reserve and maintain the natural capital of the system, local government authorities and reserve officials must work with the local communities, acknowledging their needs and rights to the use of reserve resources (such as building materials and wood for fuel from the protected forest) and remaining sensitive to the challenges presented in a postapartheid South Africa. In order to ensure management approaches are sustainable, it is therefore important to assess the effects of climate variability and climate change on the structure and availability of the system's natural capital. By embracing complexity thinking, decision makers must co-explore the system's ecological, climate and socio-economic thresholds to better inform the assessment of appropriate adaptation options aimed at preserving the natural capital and empowering communities.

\section{Incorporating regional climate downscaling}

Maslin (2004) recognised the need to think in terms of ecological thresholds, which typically combine multiple climatic factors. Yet as scientists and practitioners attempting to inform management decisions in SESs, we need to take a further step and move towards identifying system, as opposed to solely climate or ecological, thresholds. As evidenced by the complex dynamics of the Dwesa-Cwebe system, even if we could accurately predict 
the change in the likelihood of surpassing rainfall and flooding thresholds in the future, this would be insufficient information for understanding how the system might respond. However, understanding and prediction are not synonymous, and by focussing on the former we can gain valuable information while ensuring that studies of complex systems under altered climate conditions remain tractable.

Understanding how climate change may impact on SESs such as Dwesa-Cwebe relies, in part, on the ability of the scientific community to produce simulation models which adequately represent the climate system (Smith 2002; Pope et al. 2007); using model output to inform societal decision making requires models that are fit-for-purpose. Even operational weather forecast models are unable to resolve small scale atmospheric processes $(<10 \mathrm{~km})$ which are known to affect climate (e.g. cloud microphysics-Baker 1997). We certainly do not therefore expect GCMs or RCD approaches to provide the level of detail necessary to reliably forecast changes in the statistics of rainfall intensity at the Mbashe river catchment scale. Nonetheless, there are broader aspects of the regional and local climate that modelling can inform and in order to guide SES management decisions under climate change, it is important to develop models and methodologies which demonstrate the impact that an altered global climate might have at sub-global spatial scales.

According to Wilby and Pielke (2012), "for regional downscaling models to add value, they must be able to skilfully predict changes in regional weather statistics in response to human climate forcings," and Pielke (2013) notes that RCD often does not lead to improved skill in regional climate projections. Running hindcast model simulations can provide a measure of skill, and such measures are useful for informing our understanding of model accuracy and reliability in projecting changes in climate. Yet in using models to inform decision making, added value need not be constrained only to improved skill. Methods and models that help explore uncertainty as well as inform our understanding of cross-scale dependencies can also provide additional value; thus, models do not necessarily have to be more skilful in capturing changes in past atmospheric and ocean behaviour to provide added value in the context of management decisions under climate change. Indeed, all climate models, irrespective of their resolution, suffer from reliability issues owing to inherent model inadequacies, imperfect understanding of key system processes, the inability to thoroughly sample model uncertainties and a lack of adequate initialisation (Stainforth et al. 2007). Moreover, there is little agreement on metrics to separate "good" from "bad" models (Knutti et al. 2010). These errors and limitations do not disappear in RCD so can the output of RCD still add value to the study of complex SESs despite these limitations? We think the answer is yes but only if we broaden our definition of value to be more than solely improved skill in capturing past climatic behaviour.

Any RCD "forecast" will not only be model, method and scenario specific but also conditional on irreducible aleatoric uncertainties (Lorenz 1976; Pielke and Zeng 1994; Rial et al. 2004; Daron and Stainforth 2013) so our first step it to abandon our search for regional climate forecasts per se and think about RCD differently. In doing so, we might reframe our inquiry to focus on: (a) understanding how to characterise the spatial structure of climate at sub-GCM grid scales; and (b) determining how the climate at regional scales might respond under different assumptions about global climatic changes. Asking these questions will yield more insight to guide SES management decisions than asking currently unanswerable questions about how climate will change at local scales or indeed which future climates are more or less likely. By exploring the cross-scale relationships and dependencies between global and regional climate changes, using RCD methods, we can begin to better understand how climatic processes and modes of variability at these different spatial scales manifest themselves under altered forcing conditions. Consistent with the framework of Ostrom (2009), we ought therefore to be using climate model experiments at different scales to dissect the complexity of the climate system rather than to forecast its evolution.

RCMs are able to resolve processes and feedbacks that operate at a sub-grid scale GCM resolution (Giorgi 1990). Furthermore, both RCMs and ESD methods (based on empirically derived functions between large-scale predictors and local-scale predictands) can help us to better understand the how climatic uncertainties manifest themselves at different scales, such as those relevant to SES management decisions. To demonstrate that this is the case, we provide an example of three GCM models, identified here as model 1, 2 and 3 for simplicity, ${ }^{2}$ and the associated downscaled output over the target region of interest, Dwesa-Cwebe (Fig. 3). The GCM output is taken from the Coupled Model Intercomparison Project phase 5 (CMIP5) archive and the RCM downscaled output is from the COrdinated Regional Downscaling EXperiment (CORDEX) archive-further information is provided in the Supplementary Material. The green line shows the boundaries of the catchments feeding the Dwesa-Cwebe region.

Figure 3 shows a range of projections for annual precipitation change derived from direct GCM output, dynamical downscaling and ESD. In this example, we have

\footnotetext{
$\overline{2}$ Model 1 CanESM2; Model 2 = GFDL-ESM2M; Model $3=$ MIROC5.
} 
Model 1
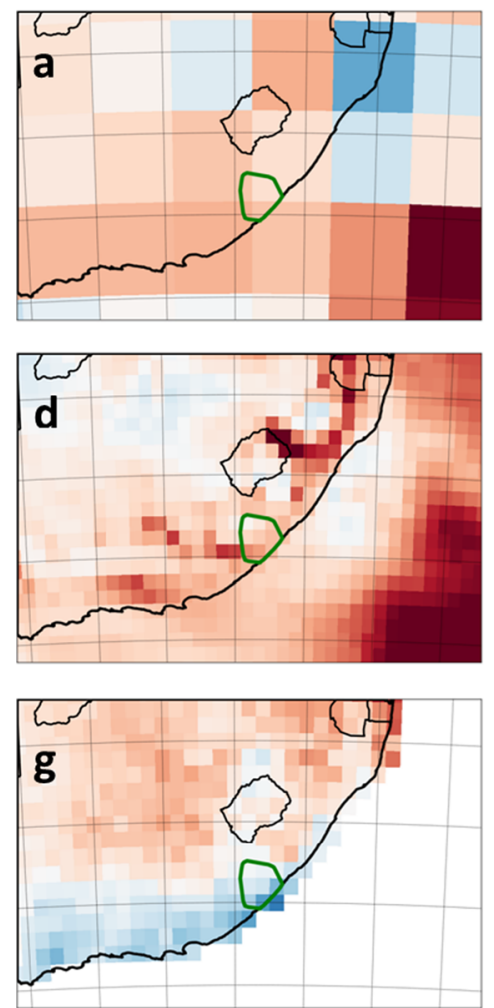

Model 2
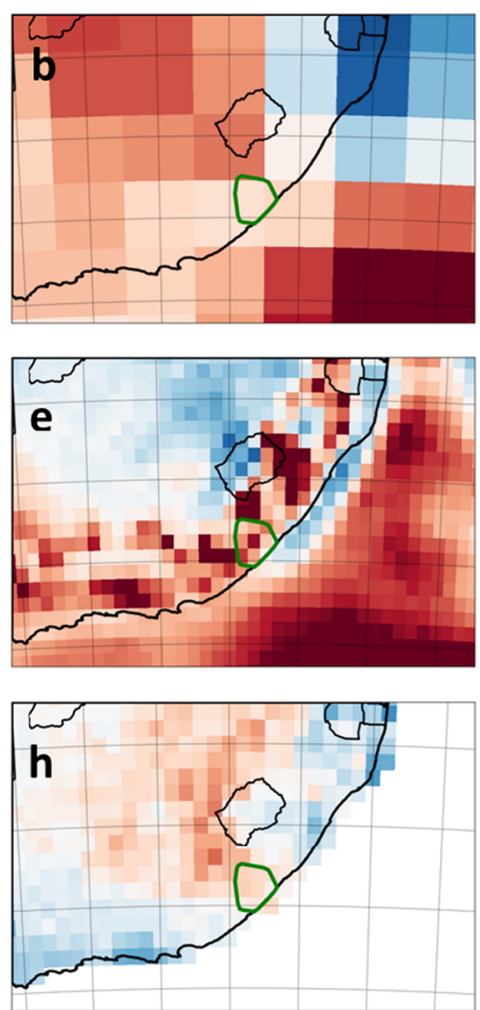

Model 3
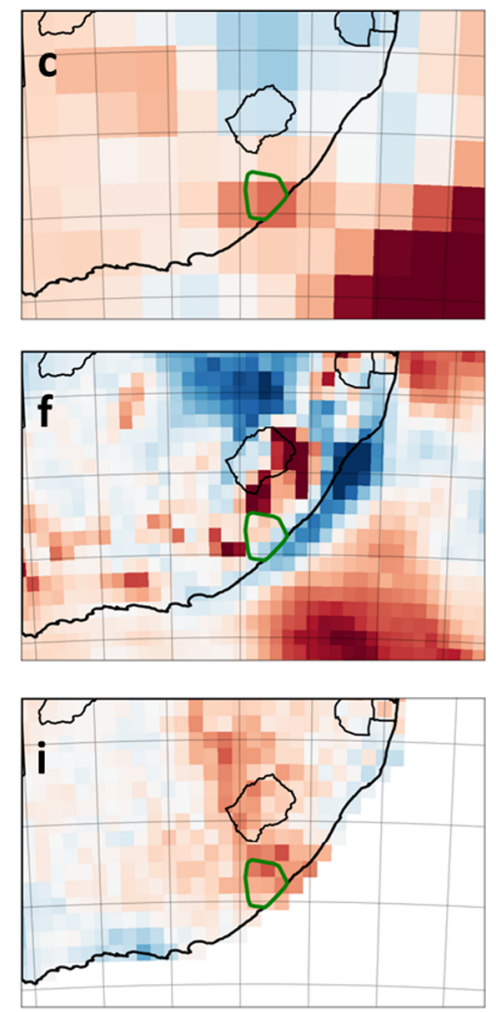

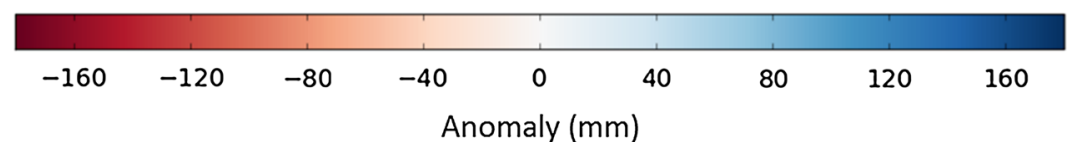

Fig. 3 Annual anomaly precipitation fields from three CMIP5 GCMs (see Supplementary Materials) for the RCP 8.5 emissions scenario for the period 2031-2060 compared to a baseline period 1961-1990. a-c Raw GCM output; $\mathbf{d}-\mathbf{f}$ and $\mathbf{g}-\mathbf{i}$ corresponding downscaled output using a RCM and ESD, respectively

in the region of interest, the dynamical downscaling conveys contrasting messages. Model 1 continues to display relatively moderate drying, while model 2 shows the potential for an increased amount of drying. Conversely, model 3 shows drying in the northern part of the DwesaCwebe region but wetting over the coastal parts. Finally, the ESD output (Fig. 3g-i) shows relatively modest changes across the whole model domain, somewhat in contrast to the GCM and dynamical downscaling results. Furthermore, the ESD broadly suggests a coastal wetting and an inland drying signal. In the Dwesa-Cwebe region, model 1 shows an increase in annual precipitation, while models 2 and 3 both show a decrease or different magnitudes.

This example serves to demonstrate the added intricacies of considering RCD output. Crucially, however, the example shows that RCD does not simply interpolate GCM fields. While the downscaling relies on the GCM output, the downscaling process can lead to qualitatively different messages about how climate might change in the future compared to those derived from assessing GCM output Mig. S2) and, for model 2 and 3 at least, wettir across the coastal region north of Dwesa-Cwebe. However, 
only. In addition, Fig. 3 shows that different methods of downscaling can result in qualitatively different climate change messages. For example, while the output from the ESD method suggests a possible systematic bias of the GCMs in the coastal region of this particular area of South Africa, it does not show the strong topographical influences that are evident in the dynamical downscaling results. We can expect higher resolution models to disagree (in part) with lower resolution models in areas of complex topography but only through examining information produced at different scales of aggregation can we begin to understand the influence of local and regional factors in the local climate response.

Now imagine you are responsible for managing the Dwesa-Cwebe road transport infrastructure with a planning time horizon of 30-40 years. You will need to ensure that any maintenance or upgrading of the infrastructure is resilient to climate change and ultimately benefits the local communities and economy. By now you understand that the system is complex and any changes may have nonlinear and unintended consequences. Even with a limited budget you have choices and there may be a number of possible adaptations, such as improving drainage in critical areas and investing in more resilient road surfaces. One of your first choices is to decide how to inform the multifaceted decision space, which includes issues such as cost (both capital and maintenance), impacts on social mobility, as well as environmental impacts and future resilience. Climate data provide only one source of information relevant to the planning decisions but choosing which information to incorporate and, crucially, how to incorporate that information is an important consideration. With or without $\mathrm{RCD}$, the challenge remains of how to use climate information in the context of a complex system and a complicated decision space. We suggest the first step is to determine whether or not decisions are at all sensitive to climate variability or climate change, establishing the key climate variables and indices (e.g. dry spell duration) that may influence vulnerabilities and affect decisions. Assuming you have decided to treat climate as an exogenous variable, you now need to understand and examine the system thresholds, composed of multivariate interactions including physical and socio-economic variables. This requires an approach in which climate and non-climate factors are considered simultaneously and mapped to the system decision space and system thresholds (e.g. Brown et al. 2012). If climate variability or changes in climate are still seen to be an important part of the decision space, then only at this point is further interrogation of the available climate data necessary.

It is important to emphasise that prior to investigating the impacts of climate change, an understanding of baseline climate risk is absolutely essential. While observational datasets are the obvious, and often most reliable, sources of information, both GCM and RCD data can also have a role in characterising the spatial dependencies of the climate, provided the models skilfully capture historical observations.

But what about the climate risks in the future, when we no longer have the luxury of observations? In the absence of RCD information, you might choose to assume that the past is sufficiently representative of the future or to focus on building resilience to a wide range of conceivable futures unconstrained by model projections. Alternatively, you might decide to use available GCM output to constrain the range of futures and examine how rainfall patterns are projected to change at the GCM scale, knowing that rainfall is a relevant variable for deciding where and how to build or upgrade infrastructure. The GCMs may provide a consistent message of drying or wetting, but are likely to disagree about the magnitudes of change, and consulting the range of projections will only provide you with a subset of the model uncertainty space. With the addition of RCD information, the range of projection uncertainty may increase or even decrease. In Fig. 3, we demonstrate how RCD translates the GCM output to higher resolutions, showing that what you might have assumed to be a consistent drying in the region may actually result in some local increases in rainfall; any plans which did not account for increasing rainfall now look to be increasingly maladaptive. It is also possible for RCD to narrow the uncertainty bounds at smaller scales. At no point are we asserting that RCD output is always more appropriate for local adaptation decisions, but rather that RCD can provide additional information in translating large-scale synoptic changes to higher resolution spatial scales. We maintain that simply viewing the downscaled output as "truth" is as foolish as taking the GCM output and doing likewise.

In the management of complex adaptive SESs, such as Dwesa-Cwebe, there is no single magic tool that can provide optimal management answers, but the most effective management processes will be iterative, consultative and holistic, and above all acknowledge the assumptions embedded in any conclusions. However, there are certainly approaches that we know to be inadequate. First and foremost, we cannot limit analyses to a one-way flow of information. Directly providing GCM or RCD output to a decision maker is an insufficient way to consider the impacts of climate change for a SES when deciding on appropriate adaptation strategies. Without a holistic understanding of how a system responds to a combination of changes in environmental and socio-economic conditions, one cannot expect the solutions to be robust and increase the resilience of the system (if that is the objective). The current prevailing paradigm of a one- 
way flow of information from the scientist to the decision maker needs to be replaced with a process that fosters a more sophisticated dialogue.

\section{The future role of regional climate downscaling}

Given the limitations associated with current RCD methods, should we continue to invest in RCMs and ESD to aid adaptation decisions, such as those related to SES management? The answer depends on what form that investment takes.

In an attempt to better inform real-world adaptation decisions, a renewed focus has been placed on the production of probabilistic information (Pittock et al. 2001; Murphy et al. 2004, 2009), to provide more information about the tails of distributions. We know, however, that no model is synonymous with the climate system so we cannot hope to achieve objective probability statements; any probabilistic information is therefore conditional on our model assumptions complicating the interpretation of such information for real-world decisions. If climate scientists wish to pursue these endeavours at regional scales, then vast amounts of additional computing capacity would be required to run the necessary model ensembles; such large ensembles may, however, be attainable within certain modelling frameworks, particularly for ESD which is computationally much more efficient than dynamical methods. Yet given the conceptual challenges of relating model probabilities to real-world probabilities, and the additional costs of creating and analysing such data, it may be worth reassessing this vision for RCD.

There are other ways in which RCD can be used to provide more value. RCD can improve our understanding of the uncertainty for climate variables relevant to SES management decisions, but this assertion is necessarily cautious. Both RCMs and ESD do not eliminate, nor even necessarily reduce, the errors and uncertainties propagated from GCMs. However, by translating the large-scale circulation changes onto regional and local domains, one can enhance understanding of how uncertainties manifest themselves at the smaller scale. To understand what information can then be reliably extracted requires scientists to place more emphasis on assessing the synoptic scale robustness of climate model output. Determining truly robust management interventions is only possible if we can project climate at the relevant spatial and temporal scales, while ensuring our exploration of uncertainty is sufficiently comprehensive. Downscaling should help us to further explore uncertainty in climate projections and provides a means to generate information at more policy-relevant spatial scales. However, given the limitations, any RCD projections must be used with caution and RCD methods need to be continually assessed for skill in predicting changes in climate before they can be considered fit-forpurpose for use in projecting future climate change. Furthermore, such endeavours are constrained by limited computational capacity and the ability to manage and interpret large volumes of model output data.

Over the next decade, climate modelling institutions are likely to continue increasing the spatial resolution of RCMs in the hope of improving their representation of sub-grid scale processes. Yet the model output will continue to be dependent on the output of lower resolution GCMs and the quality of the exogenous drivers. While GCMs may be developed to explicitly include more processes in addition to increasing their spatial resolution, they will continue to be imperfect representations of the climate system and uncertainty will remain an inherent part of climate modelling; indeed, recent evidence from the from the Fifth Assessment Report of the IPCC shows that scientists may, in many cases, be unable to further constrain the uncertainty in future model projections (IPCC 2013). We cannot expect RCD projections to become entirely accurate and climate model simulations will, at best, only help in approximating the true uncertainty space. Failure to recognise these constraints may potentially risk the implementation of maladaptive climate change strategies.

On the other hand, as more research is conducted our understanding of the dynamics and predictability of the climate system should improve. Assuming an increase in computational capacity, models will be able to explicitly resolve and (presumably) better simulate more processes relevant to regional climates. The dialogue between climate scientists and the users of climate information should have matured. As climate scientists engage further with different disciplines, there ought to be more recognition of the different ways of framing decision making processes. And with the increase in resources committed to climate services, users should have better access to climate information as well as an improved understanding of climate risks and the limits to climate information. If this more optimistic vision of the future is to become a reality, we must continue to debate how best to develop and use RCD to meet the needs of society.

As we have discussed here, solutions to management problems in SESs require an interdisciplinary perspective. Hulme (2005) recognises the role of ecologists in thinking beyond individual species and considering system scale solutions. Similarly, climate adaptation scientists and practitioners must aim to think more broadly about the vulnerability of systems to factors other than climate (Füssel 2007). Unifying RCD output with other sources of information in the context of managing complex adaptive SESs remains a challenge. However, we believe this 
challenge is not insurmountable if one acknowledges ignorance and applies an assess-risk-of-policy framing (Pielke et al. 2012). We cannot, and probably never will, accurately predict the future climate at regional and local scales, let alone predict the evolution of complex dynamic SESs, so adopting a predict-then-act approach will only ever be of limited value. That said, the assess-risk-of-policy framing still typically relies, in part, on model projections and future scenarios (though such scenarios can be determined using a weather generator approach-e.g. Steinschneider and Brown 2013) to test the robustness of policy interventions; here, RCD has an important role to play in understanding the complexities of the scaledependent climate system and in helping to identify possible climate futures that are worth incorporating in decision processes.

Is there an important role for RCD in SES management decisions in the future? We believe there is but our approaches cannot simply extrapolate from current practices which largely focus on data provision and a one-way flow of information. Lessons from how RCD is used need to guide model development and inform different modes of dissemination. Future research and practices that explore the concept of system thresholds and fully embrace multidisciplinary perspectives are likely to yield further useful insights to guide the management of SESs. The challenge of how to organise and bring together people with different disciplinary and experiential perspectives remains nontrivial but failure to do so risks the implementation of maladaptive policies and decisions. Management decisions in SESs vulnerable to climate change will be most effective when they incorporate holistic analyses of system sensitivities and thresholds rather than rely on segmented efforts to predict the future of different system variables in isolation.

Acknowledgments The authors would like to acknowledge the helpful input of Lisa Coop, Chris Lennard and Piotr Wolski. Funding support for the research was provided by the Climate System Analysis Group at the University of Cape Town.

Open Access This article is distributed under the terms of the Creative Commons Attribution License which permits any use, distribution, and reproduction in any medium, provided the original author(s) and the source are credited.

\section{References}

Adger NW (2000) Social and ecological resilience: are they related? Prog Hum Geogr 24:347-364

Adger WN, Arnell NW, Tompkins EL (2005) Successful adaptation to climate change across scales. Glob Environ Change 15(2):77-86

AESEDA (2014) Parks and people: South Africa Wild Coast. Programme from Penn State Engagement in Africa. http:// aeseda.psu.edu/programs/parks-and-people-south-africa. Accessed 8 Apr 2014

Agrawal A (2010) Local institutions and adaptation to climate change. In: Smith J (ed) Social dimensions of climate change: equity and vulnerability in a warming world. The International Bank for Reconstruction and Development/The World Bank, pp 173-197

Baker MB (1997) Cloud microphysics and climate. Science 276:1072-1078

Batlle Bayer L, van den Hurk BJJM, Strengers BJ, van Mlnnen JG (2012) Regional feedbacks under changing climate and land-use conditions. Earth Syst Dyn Discuss 3:201-234

Benestad RE (2004) Empirical-statistical downscaling in climate modelling. EOS Trans AGU 85(42):417-422

Berkes F, Colding J, Folke C (2003) Navigating social ecological systems, building resilience for complexity and change. Cambridge University Press, New York

Bonan GB (2008) Forests and climate change: forcings, feedbacks, and the climate benefits of forests. Science 320(5882):1444-1449

Brown C, Ghile Y, Laverty M, Li K (2012) Decision scaling: linking bottom-up vulnerability analysis with climate projections in the water sector. Water Resour Res 48(9):W09537

Burkett VR, Wilcox DA, Stottlemyer R, Barrowa W, Fagred D, Barone $J$, Price $J$, Nielsen JL, Allen CD, Peterson DL, Ruggerone G, Doyle T (2005) Nonlinear dynamics in ecosystem response to climatic change: case studies and policy implications. Ecol Complex 2(4):357-394

Cilliers P (1998) Complexity and postmodernism: understanding complex systems. Routledge, London

Daron J (2012) Examining the decision relevance of climate model information for the insurance industry. Ph.D. thesis, London School of Economics, UK

Daron J, Stainforth D (2013) On predicting climate under climate change. Environ Res Lett 8(3):034021

Department of Land Affairs (2001) The Dwesa-Cwebe community land restitution claim. Settlement agreement, section 42D of the 1994 Restitution of Land Rights Act No. 22. Unpublished report, Regional Land Claims Commission, East London

Fay DA (2007) Struggles over resources and community formation at Dwesa-Cwebe, South Africa. Int J Biodivers Sci Manag 3:88-101

Fay DA (2011) Post-apartheid transformations and population change around Dwesa-Cwebe Nature Reserve, South Africa. Conserv Soc 9(1):8-15

Fox R (1997) The geography of the Dwesa-Cwebe area: the role of GIS mapping. In: Palmer R, Timmermans H (eds) Indigenous knowledge, conservation reform, natural resource management and rural development in the Dwesa and Cwebe Nature Reserves and neighbouring village settlements. Institute of Social and Economic Research, Rhodes University, Grahamstown, pp 25-37

Frey-Buness F, Heimann D, Sausen R (1995) A statistical-dynamical downscaling procedure for global climate simulations. Theor Appl Climatol 50(3-4):117-131

Funtowicz S, Ravetz JR (1994) Emergent complex systems. Futures 26(6):568-582

Füssel HM (2007) Vulnerability: a generally applicable conceptual framework for climate change research. Glob Environ Change 17:155-167

Gao X, Zhang D, Chen Z, Pal JS, Giorgi F (2007) Land use effects on climate in China as simulated by a regional climate model. Sci China Ser D Earth Sci 50(4):620-628

Giorgi F (1990) On the simulation of regional climate using a limited area model nested in a general circulation model. J Clim 3:941-963

Haken H, Mikhailov AS (eds) (1993) Interdisciplinary approaches to nonlinear complex systems. Springer series in Synergetics. Springer, Berlin, Heidelberg 
Hewitson BC, Crane RG (2006) Consensus between GCM climate change projections with empirical downscaling: precipitation downscaling over South Africa. Int J Clim 26(10):1315-1337

Hewitson BC, Daron J, Crane RG, Zermoglio F, Jack C (2013) Interrogating empirical-statistical downscaling. Clim Change 122(4):539-554

Holling CM (1986) The resilience of terrestrial ecosystems: local surprise and global change. In: Clark WC, Munn RE (eds) Sustainable development of the biosphere. Cambridge University Press, Cambridge, pp 292-317

Hulme PE (2005) Adapting to climate change: is there scope for ecological management in the face of a global threat? J Appl Ecol 42:784-794

IPCC (2013) Climate Change 2013: Working Group I-the physical science basis. In: Stocker T et al (eds) IPCC Fifth Assessment Report (AR5). Cambridge Univ Press, New York

Jenson HJ (1998) Self-organized criticality: emergent complex behavior in physical and biological systems. Cambridge Lecture Notes in Physics, Cambridge University Press, Cambridge, UK

Kastens KA, Maduca CA, Cervato C, Frodeman R, Goodwin C, Liben LS, Mogk DW, Spangler TC, Stillings NA, Titus S (2009) How geoscientists think and lean. EOS Trans AGU 90(31):265-272

Kepe T (2005) Grasslands ablaze: vegetation burning by rural people in Pondoland, South Africa. S Afr Geogr J 87:10-17

Klein JT (2004) Interdisciplinarity and complexity: an evolving relationship. Emerg Complex Organ 6(1-2):2-10

Knutti R, Furrer R, Tebaldi C, Cermak J, Meehl GA (2010) Challenges in combining projections from multiple climate models. J Clim 23:2739-2758

Lempert R, Nakicenovic N, Sarewitz D, Schlesinger M (2004) Characterizing climate-change uncertainties for decision-makers. Clim Change 65:1-9

Lorenz EN (1976) Nondeterministic theories of climate change. Quat Res 6:495-506

Lorenz EN (1995) Climate is what you expect. Presented at NCAR colloquium. http://eaps4.mit.edu/research/Lorenz/Climate_ expect.pdf, Accessed on 8 Apr 2014

Maslin M (2004) Ecological versus climatic thresholds. Science 306:2197-2198

McAllister P (1999) Agriculture and co-operative labour in Shixini Village, Transkei. Working Paper 33. Afrika Studie Centrum, Leiden

Murphy J (2000) Predictions of climate change over Europe using statistical and dynamical downscaling techniques. Int J Climatol 20:489-501

Murphy J, Sexton D, Barnett D, Jones G, Webb M, Collins M (2004) Quantification of modelling uncertainties in a large ensemble of climate change simulations. Nature 430:768-772

Murphy J et al (2009) UK Climate Projections Science Report: climate change projections, 2009. Met Office Hadley Centre, Exeter

Mustelin J, Kuruppu N, Matus Kramer A, Daron J, de Bruin K, Guerra-Noriega A (2013) Climate adaptation research for the next generation. Clim Dev 5(3):189-193

O'Brien KL, Eriksen S, Nygaard L, Schjolden A (2007) Why different interpretations of vulnerability matter in climate change discourses. Clim Policy 7(1):73-88

Ohl C, Krauze K, Grünbühel C (2007) Towards an understanding of long-term ecosystem dynamics by merging socio-economic and environmental research: criteria for long-term socio-ecological research sites selection. Ecol Econ 63(2-3):383-391

Ostrom E (2009) A general framework for analysing sustainability of social-ecological systems. Science 325:419-422

Palmer R, Timmermans H, Fay D (2002) From conflict to negotiation. Nature-based development on the South African Wild Coast. Human Sciences Research Council, Pretoria
Peters DPC, Pielke RA Sr, Bestelmeyer BT, Allen CD, MunsonMcGee S, Havstad KM (2004) Cross scale interactions, nonlinearities, and forecasting catastrophic events. Proc Natl Acad Sci 101(42):15130-15135

Peters DPC, Bestelmeyer BT, Turner MG (2007) Cross-scale interactions and changing pattern-process relationships: consequences for system dynamics. Ecosystems 10(5):790-796

Pielke RA Sr (2013) Climate vulnerability, understanding and addressing threats to essential resources, 1st edn. Academic Press, London

Pielke RA Sr, Zeng X (1994) Long-term variability of climate. Am Meteor Soc 51(1):155-159

Pielke RA Sr, Marland G, Betts RA, Chase TN, Eastman JL, Niles JO, Niyogi DS, Running SW (2002) The influence of land-use change and landscape dynamics on the climate system: relevance to climate-change policy beyond the radiative effect of greenhouse gases. Philos Trans R Soc A 360(1797): 1705-1719

Pielke RA Sr, Wilby R, Niyogi D, Hossain F, Dairuku K, Adegoke J, Kallos G, Seastedt T, Suding K (2012) Dealing with complexity and extreme events using a bottom-up, resource-based vulnerability perspective. Geophys Mon Ser 196:345-359

Pittock AB, Jones RN, Mitchell C (2001) Probabilities will help us plan for climate change. Nature 413:249

Pope V, Brown S, Clark R, Collins M, Collins W, Dearden C, Gunson J, Harris G, Jones C, Keen A, Lowe J, Ringer M, Senior C, Sitch S, Webb M, Woodward S (2007) The Met Office Hadley Centre climate modelling capability: the competing requirements for improved resolution, complexity and dealing with uncertainty. Philos Trans R Soc A 365(1860):2635-2657

Preuschmann S, Jacob D (2012) LUCHS-an approach to introduce Land Use Changes in a regional climate models by using EO data. EGU General Assembly Abstract Proceedings, 10364

Randall DA, Wood RA, Bony S, Colman R, Fichefet T, Fyfe J, Kattsov V, Pitman A, Shukla J, Srinivasan J, Stouffer RJ, Sumi A, Taylor KE (2007) Climate models and their evaluation. In: Solomon S, Qin D, Manning M, Chen Z, Marquis M, Averyt KB, Tignor M, Miller HL (eds) Climate Change 2007: the physical science basis. Contribution of Working Group I to the Fourth Assessment Report of the Intergovernmental Panel on Climate Change. Cambridge University Press, Cambridge

Resilience Alliance (2010) Assessing resilience in social-ecological systems: Workbook for practitioners. Version 2.0

Rial J et al (2004) Nonlinearities, feedbacks and critical thresholds within the earth's climate system. Clim Change 65:11-38

Rind D (1999) Complexity and climate. Science 284:105-117

Smith L (2002) What might we learn from climate forecasts? Proc Natl Acad Sci 99(1):2487-2492

Stainforth D, Allen M, Tredger E, Smith L (2007) Confidence, uncertainty and decision-support relevance in climate predictions. Philos Trans R Soc A 365:2145-2161

Steinschneider S, Brown C (2013) A semiparametric multivariate, multi-site weather generator with low-frequency variability for use in climate risk assessments. Water Resour Res 49:7205-7220

Stockholm Resilience Centre (2007) What is resilience? http://www. stockholmresilience.org/21/research/what-is-resilience.html. Accessed on 8 Apr 2014

Taylor KE, Stouffer RJ, Meehl GA (2012) An overview of CMIP5 and the experiment design. Bull Am Meteor Soc 93:485-498

Timmermans HG (2004) Rural livelihoods at Dwesa/Cwebe: poverty, development and natural resource use on the Wild Coast, South Africa. M.Sc. thesis, Rhodes University

Timmermans HG, Naicker K (2002) The land. In: Palmer R, Timmermans H, Fay D (eds) From conflict to negotiation. Nature-based development on the South African Wild Coast. Human Sciences Research Council, Pretoria, pp 2-14 
UN-REDD (2012) The UN-REDD programme strategy 2011-2015. The United Nations collaborative programme on reducing emissions from deforestation and forest degradation in developing countries

Wilby RL, Dessai S (2010) Robust adaptation to climate change. Weather 65(7):180-185
Wilby RL, Pielke RA Sr (2012) Regional climate downscaling: what's the point? EOS Trans AGU 93(5):52

Young OR, Berhout F, Gallopin GC, Jansen MA, Ostrom E, van der Leeuw S (2006) The globalization of socio-ecological systems: an agenda for scientific research. Glob Environ Change 16(3):304-316 